\title{
Genetic Engineering of Bacteriophages Against Infectious Diseases
}

\author{
Yibao Chen 1,2, Himanshu Batra ${ }^{3}$, Junhua Dong ${ }^{1,2}$, Cen Chen ${ }^{1,2}$, Venigalla B. Rao ${ }^{3}$ and \\ Pan Tao ${ }^{1,2,3 *}$ \\ ${ }^{1}$ College of Veterinary Medicine, Huazhong Agricultural University, Wuhan, China, ${ }^{2}$ The Cooperative Innovation Center for \\ Sustainable Pig Production, Huazhong Agricultural University, Wuhan, China, ${ }^{3}$ Department of Biology, The Catholic University \\ of America, Washington, DC, United States
}

Bacteriophages (phages) are the most abundant and widely distributed organisms on Earth, constituting a virtually unlimited resource to explore the development of biomedical therapies. The therapeutic use of phages to treat bacterial infections ("phage therapy")

OPEN ACCESS

Edited by:

Mattias Collin,

Lund University, Sweden

Reviewed by:

Andrzej Gorski,

Ludwik Hirszfeld Institute of

Immunology and Experimental

Therapy (PAN), Poland

Chung-Yin Leung,

Georgia Institute of Technology,

United States

*Correspondence:

Pan Tao

taopan@mail.hzau.edu.cn

Specialty section:

This article was submitted to

Infectious Diseases,

a section of the journal

Frontiers in Microbiology

Received: 21 February 2019

Accepted: 15 April 2019

Published: 03 May 2019

Citation:

Chen Y, Batra H, Dong J, Chen C,

Rao VB and Tao P (2019) Genetic

Engineering of Bacteriophages Against Infectious Diseases.

Front. Microbiol. 10:954.

doi: 10.3389/fmicb.2019.00954 was conceived by Felix d'Herelle nearly a century ago. However, its power has been realized only recently, largely due to the emergence of multi-antibiotic resistant bacterial pathogens. Progress in technologies, such as high-throughput sequencing, genome editing, and synthetic biology, further opened doors to explore this vast treasure trove. Here, we review some of the emerging themes on the use of phages against infectious diseases. In addition to phage therapy, phages have also been developed as vaccine platforms to deliver antigens as part of virus-like nanoparticles that can stimulate immune responses and prevent pathogen infections. Phage engineering promises to generate phage variants with unique properties for prophylactic and therapeutic applications. These approaches have created momentum to accelerate basic as well as translational phage research and potential development of therapeutics in the near future.

Keywords: bacteriophages, genome engineering, vaccine platform, phage therapy, infectious disease

\section{INTRODUCTION}

Bacteriophages (phages), discovered in the early 20th century independently by Frederick Twort and Felix d'Herelle, are the most abundant organisms on earth with up to $2.5 \times 10^{8}$ phages per $\mathrm{ml}$ in natural waters (Bergh et al., 1989). It is well accepted that phages specifically infect bacteria and, therefore, were considered for the development of natural approaches to treat bacterial infections since their discovery (Wittebole et al., 2014; Salmond and Fineran, 2015). However, due to the discovery of antibiotics that provided greater breadth and potency, phage therapy lagged behind although research continued in some Eastern European countries (Chanishvili, 2012, 2016; Wittebole et al., 2014). Therefore, in the following several decades, phages were mainly used as model organisms to explore the basic mechanisms of life and led to the birth of modern molecular biology. One classical example is the demonstration of a central biological question in the early 20th century, the nature of a gene, by 
"Hershey-Chase experiment" (also called "Waring blender experiment") (Salmond and Fineran, 2015). This elegant experiment demonstrated that DNA, not protein, is the genetic material of T2 phage.

Recently, the emergence of multi-antibiotic resistant bacterial pathogens and the low rate of new antibiotic discovery brought new urgency to develop phage-based therapies ( $\mathrm{Lu}$ and Koeris, 2011; Viertel et al., 2014; Domingo-Calap and DelgadoMartinez, 2018). A striking example is the recent San Diego patient who was infected by multi-drug resistant Acinetobacter baumannii stain during travelling to Egypt. The patient went into a coma for nearly 2 months but awoke 2 days after intravenous injection of a phage cocktail that lyses this bacterium and finally completely recovered (Schooley et al., 2017). With recent advances, particularly the genome engineering (Martel and Moineau, 2014; Ando et al., 2015; Lemay et al., 2017; Tao et al., 2017b; Kilcher et al., 2018), the applications of phages have greatly expanded. In addition to its use in antibacterial therapy, phages were used in synthetic biology (Lemire et al., 2018), material science (Cao et al., 2016), and biomedical fields (Cao et al., 2018; Tao et al., 2018c). Considering the abundance and diversity, there is vast potential to engineer phages for different applications. In this review, we will focus on the applications of phages in infectious disease, in particular, vaccine development and phage therapy. We will discuss the phage engineering strategies and how these can equip the phages with the ability to advance the vaccine and phage therapy fields.

\section{PHAGE GENOME ENGINEERING}

\section{Traditional Homologous Recombination-Based Techniques}

Homologous recombination refers to the exchange of nucleotide sequences between two DNA molecules, which share similar or identical sequences. It is a naturally occurring biological event and was employed in the first-generation strategy for engineering phage genomes. This classical genetic strategy (called phage crosses) was used as a standard way to generate a mutant phage with specific phenotypes by either combining or separating mutations from two parental phages (Figure 1A; Karam et al., 1994). Host cells were co-infected with two parental phages, which at least have two selective markers (or phenotypes). The homologous recombination will occur between parental phage genomes. The progeny phages were then screened for the desired phenotype(s), and the recombinants with appropriate phenotypes were purified for further analysis. Obviously, this approach was mainly used to exchange or combine the phenotypes of parental phages

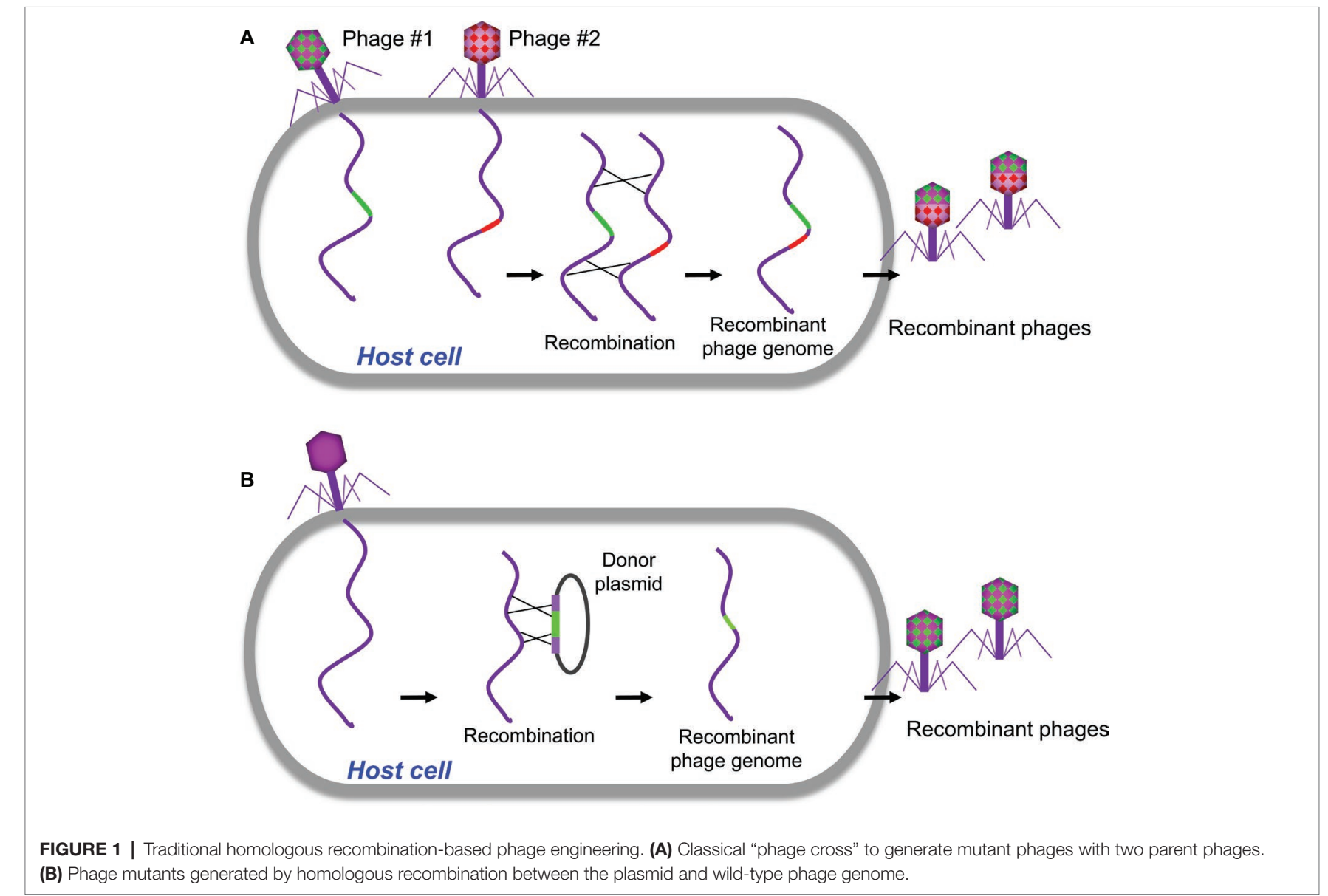


and was unable to do specific modification to the targeted site in phage genome, which limits the use of the method.

Homologous recombination between the plasmid and phage genome was then developed to generate recombinant phages with gene replacements, deletions, or insertions (Sarkis et al., 1995; Rao and Mitchell, 2001; Oda et al., 2004; Tanji et al., 2004; Namura et al., 2008). In a standard procedure, the plasmid containing a designed mutation flanked by homologous sequences of phage is constructed and transformed into host bacteria, which is then infected with the phage to be engineered (Figure 1B). The resulted recombinant phages containing the desired mutations were then screened. Although higher recombination rates up to $5 \times 10^{-3}$ were reported for the some phages (Oda et al., 2004), overall the frequencies of recombination are quite low (Sarkis et al., 1995; Tanji et al., 2004). Therefore, this classical genetic strategy is tedious and time-consuming to find the desired recombinants unless there is a selection strategy for the recombinant phage.

\section{Bacteriophage Recombineering of Electroporated DNA (BRED)}

Recombineering is also a homologous recombination-based technique but exploits a phage-encoded recombination system such as Red system of phage lambda and RecE/RecT system of Rac prophage to enhance the frequency of homologous recombination (Poteete, 2001; Murphy, 2012; Nafissi and Slavcev, 2014). Red system is a well-studied phage recombination system composing the gam $(\gamma)$, exo $(\alpha)$, and bet $(\beta)$ genes. Gam inhibits E. coli RecBCD exonuclease complex to prevent degradation of the liner dsDNA substrate (Poteete, 2001). Exo targets double-stranded DNA (dsDNA) ends to degrade one strand of DNA in a $5^{\prime}$ to $3^{\prime}$ manner to generate a single-stranded DNA (ssDNA) substrate. Beta is an ssDNA-binding protein that anneals the ssDNA substrate to its recombination target in phage genome.

Similar to the plasmid-based homologous recombination mentioned above, BRED requires co-electroporation of the phage DNA template and donor DNA into bacterial cells expressing proteins such as RecE/RecT-like proteins via either plasmid or chromosomally inserted genes to promote homologous recombination (Marinelli et al., 2008, 2012; Thomason et al., 2009). The donor DNA contains the desired mutations flanked by homologous sequences of phage to be engineered, which lead to the homologous recombination occurring between phage genome and donor DNA. It was suggested that recombination happens only after phage genome replication has begun (Marinelli et al., 2008). Therefore, wild-type phages will be also recovered along with the mutant phages, and the generated plaques contain a mixture of wild-type and mutant phages. When using this method to engineer mycobacteriophage Giles, the mutantcontaining plaques can be recovered at an efficiency of 3.4-22.2\% (Marinelli et al., 2008). However, after initial PCR screening of plaques containing mutants, further purification are needed to isolate a homogenous phage mutant (Marinelli et al., 2008). This method was first developed for mycobacteriophage and was later on adapted to many other phages to construct gene deletions, replacements, and heterologous gene insertions (Thomason et al., 2009; Marinelli et al., 2012). However, it highly relies on co-transformation of phage DNA and donor DNA into the same cell, which is generally low. Therefore, this method is especially difficult to use in Gram-positive bacteria that exhibit low transformation efficiencies. Instead of co-transformation of phage DNA and donor DNA, bacteria that contain phage-encoded recombination system can be transformed only with donor DNA (Oppenheim et al., 2004; Pan et al., 2017). The phage mutants will be then generated by infecting bacterial cells with WT phage. This will overcome the transformation limit of BRED to some extent. However, high background of WT phage is expected, thus extensive screening of recombinants is required.

\section{CRISPR-Cas-Based Phage Engineering}

Clustered regularly interspaced short palindromic repeats (CRISPR)-Cas system, firstly discovered at the end of last century, is an immune system of prokaryote to counter the invasions. Recently, it was adapted for genome engineering in many organisms including phages (Figure 2; Box et al., 2016; Bari et al., 2017; Tao et al., 2017b; Hatoum-Aslan, 2018; Hupfeld et al., 2018; Knott and Doudna, 2018; Schilling et al., 2018; Shen et al., 2018). The effector complexes of CRISPR-Cas system contain two main components, Cas proteins and CRISPR RNA (crRNA). The effector complexes specifically bind to their target sequences mediated by the crRNA with a region complementary to the target DNA where Cas protein cleaves the DNA and creates a double-strand DNA break (Shmakov et al., 2017; Knott and Doudna, 2018). The CRISPR-Cas system can be classified into six types and further cataloged into two broad classes (Class 1 or 2) based on phylogeny and activity mechanisms (Koonin et al., 2017). Class 1 systems, including types I, III, and IV, employ effector complexes containing multiple Cas proteins, while class 2 systems, including types II, V, and VI, employ effector complexes containing a single Cas protein to cleave the target DNAs (Koonin et al., 2017).

CRISPR-Cas system was first applied to phage genome editing in 2014 to select a T7 phage mutant with a deletion of a nonessential gene, gene1.7 (Kiro et al., 2014). In this study, CRISPR-Cas system was used as a screening tool to eliminate the WT phage from the recombinants. This plasmidbased type I CRISPR-Cas system, which was targeted to gene 1.7, was able to cleave WT genome and eliminate WT T7 phages. In contrast, the mutant phages lacking gene 1.7 were resistant to Cas9 complex and could propagate normally (Kiro et al., 2014). Later on, type I CRISPR-Cas system from Vibrio cholerae was identified and used for engineering of $V$. cholerae lytic phage (Box et al., 2016). In this system, both donor DNA and CRISPR-Cas components were assembled in a single plasmid. Propagation of phages on $V$. cholerae harboring this plasmid led to the cleavage of phage genome by CRISPR-Cas, which was repaired by homologous recombination with the donor DNA and resulted in recombinant phages with deletion or insertion mutations (Box et al., 2016). 


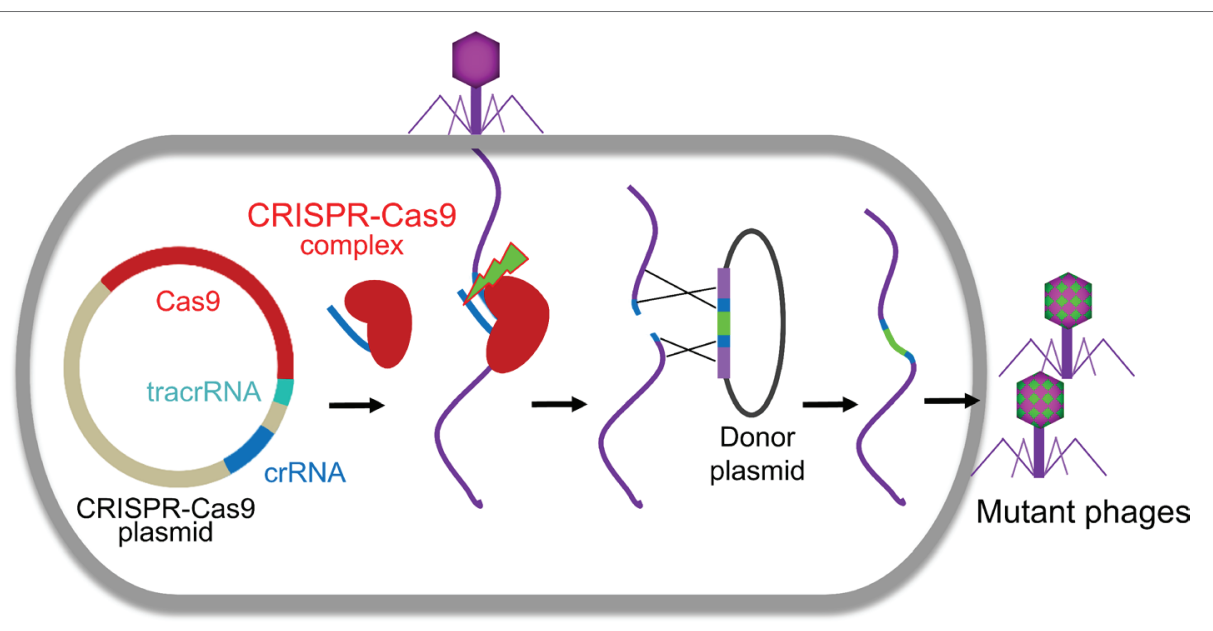

FIGURE 2 | CRISPR-Cas-based phage engineering. The formed CRISPR-Cas9 complex specifically binds to the target site in the phage genome and creates a double-strand DNA break during phage infection. The mutations were introduced into the donor plasmid. The DNA break can be repaired by recombination with the donor to generate mutants of interest.

Although the first type II CRISPR-Cas system used for phage editing was from Streptococcus thermophiles (Martel and Moineau, 2014), Streptococcus pyogenes CRISPR-Cas is most often used for phage genome engineering (Lemay et al., 2017; Tao et al., 2017b; Schilling et al., 2018; Shen et al., 2018). Recently, CRISPR-Cas of Listeria monocytogenes was also identified and used to develop an effective engineering platform for Listeria phages (Hupfeld et al., 2018). Usually, all three components of CRISPR-Cas system, Cas9, crRNA, and trans-activating crRNA (tracrRNA), were cloned into a single plasmid. The crRNA and tracrRNA could be either expressed separately (Lemay et al., 2017; Tao et al., 2017b) or as a single fusion RNA (Schilling et al., 2018). After transform into host cells, all the components were expressed and formed a CRISPR-Cas9 complex, which will specifically bind to the target site in the phage genome and creates a double-strand DNA break during phage infection (Figure 2). Due to the absence or low efficiency of non-homologous end joining (NHEJ) repairing systems in bacteria (Brissett and Doherty, 2009), the cleavage of CRISPR-Cas9 complex is usually lethal to the phage (Tao et al., 2017b, 2018b). When the homologous donor is provided, the DNA break can be repaired by recombination with the donor to generate mutants of interest. We found that the $S$. pyogenes Cas9 complex can even efficiently cleave T4 phage genome, which is highly resistant to most restriction endonucleases due to the covalent modifications (5-hydroxymethylation and glucosylation) to its cytosines (Tao et al., 2017b, 2018b). However, the cleavage efficacy of CRISPR-Cas9 complex depends on the selected crRNA (Tao et al., 2017b, 2018b). When the crRNA targeting site (protospacer sequence) in the phage genome is highly vulnerable to cleavage by Cas9 complex (high restriction spacer), only the recombinant phages can survive. Therefore, all resultant progeny phages are recombinant mutants. However, if the protospacer is poorly cleaved (low restriction spacer) or an overdose of parental phages were used for infection, it could lead to error-prone repair and incorporation of random mutations in the protospacer sequence resulting in escape from CRISPR-Cas cleavage (Martel and Moineau, 2014; Tao et al., 2018b). This was reported in both types I and II CRISPR-Cas systems (Barrangou et al., 2007; Fineran et al., 2014).

The type III CRISPR-Cas system was also used for engineering virulent staphylococcal phages. This method utilizes the native endogenous CRISPR-Cas10 system of Staphylococcus epidermidis but supplemented with the crRNA transcribed from an exogenous plasmid (Bari et al., 2017). This CRISPR-Cas 10 system has high cleavage efficacy and affords S. epidermidis complete protection against a high dose of staphylococcal phages (Andhra and ISP) infection when coding strand is targeted. The donor DNA was also cloned into the same plasmid expressing crRNA. Infection S. epidermidis containing this plasmid with staphylococcal phages was able to generate progenies. Strikingly, all the tested progeny phages acquired the desired mutations (Bari et al., 2017).

\section{Rebooting Phages Using Assembled Phage Genomic DNA}

In principle, all the methods mentioned above are based on the homologous recombination. Alternatively, engineered phages can be directly generated by transforming the host cells with naked full-length phage genomic DNA containing the desired mutations (Figure 3). Replication, transcription, and translation of genomic DNA in the host cells will lead to the assembly of infectious phages. For phages with small genome such as phiX174 (5,386 bp), the genomic DNA can be assembled in vitro via polymerase cycling assembly (PCA) using synthetic oligonucleotides that span the whole genome with overlap sequences (Smith et al., 2003; Mamedov et al., 2007). For phages with larger genomes such as T7 (39,937 bp), 


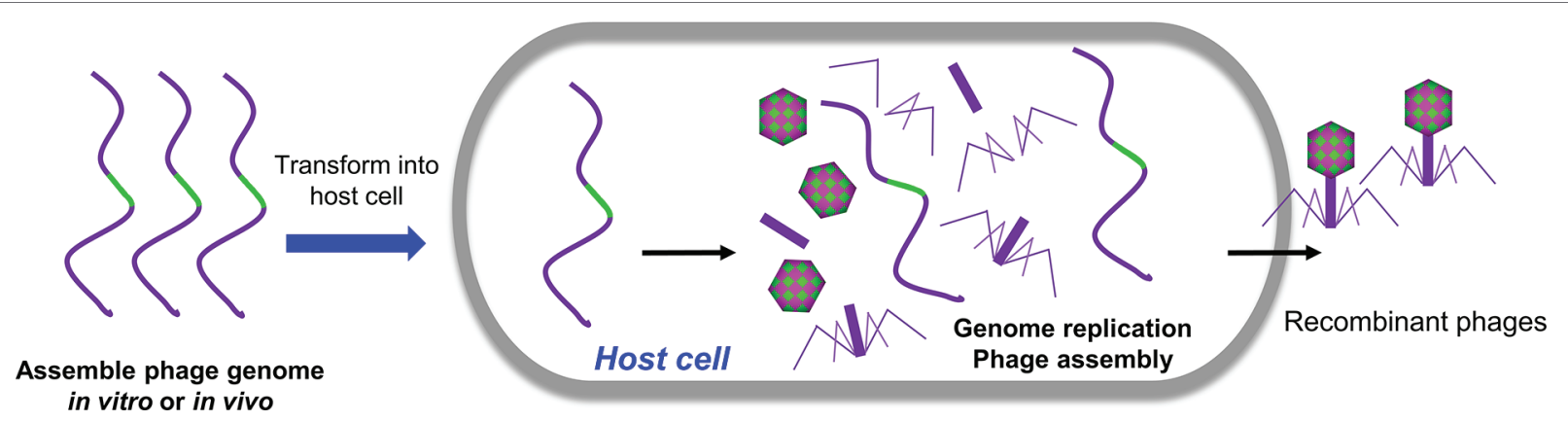

FIGURE 3 | Rebooting phages using assembled phage genomic DNA. The phage genome DNA with desired mutations was assembled in vivo or in vitro and was transformed into host cells. The replication, transcription, and translation of genomic DNA in the host cells will lead to the assembly of infectious phages.

the genomic DNA can be assembled in vitro through ligation of individual genome fragments cut with specific restriction enzymes (Chan et al., 2005). Alternatively, the full-length genomic DNA can be assembled with overlapping genome fragments in vivo through transformation-associated recombination (TAR), which exploits a high level of homologous recombination in the yeast (Jaschke et al., 2012; Ando et al., 2015). The TAR approach has been used to assemble large DNA up to $300 \mathrm{~kb}$ in length (Hou et al., 2016; Shang et al., 2017). The overlapping viral fragments were amplified from the genome by PCR, and each adjacent fragment has a homologous sequence overhang. The first and last phage fragments contain homology sequences with yeast vector. When transformed into yeast cells, the fragments were recombined to form a complete phage genome in a yeast vector. The DNA was then extracted from yeast and transformed into host cells to generate phages. Mutations can be introduced into any of the fragment(s) to generate desired phage mutants.

Gram-positive bacteria usually exhibit low transformation efficiencies. A recent study indicated that it is also possible to efficiently reboot phages of Gram-positive bacteria using L-form bacteria as rebooting compartments (Kilcher et al., 2018). L-form bacteria are cell wall-deficient bacteria, which, unlike its parent cells, have the ability to take up large DNA such as phage genome DNA. It was shown that L-form Listeria can be employed not only for rebooting of Listeria phages but also enable cross-genus rebooting of Bacillus and Staphylococcus phages (Kilcher et al., 2018).

\section{APPLICATIONS OF PHAGES IN INFECTIOUS DISEASE}

Infectious diseases can be treated before (prophylaxis) or after (therapy) infection, where phages can contribute at both levels to treat bacterial infections (Debarbieux et al., 2010; Chanishvili, 2016; Tao et al., 2018c). Phages have been used to eliminate bacterial pathogens since their discovery last century. Recent studies also indicated their high potential to be developed as vaccine platforms, which can be used to prevent both bacterial and viral pathogens. Here, we discuss the characters that make phages good candidates against infectious diseases either as vaccine platform or as phage therapy. Phage engineering technologies allow generate variants with unique properties and help minimum the features that might hamper the applications of phage for prophylactic and therapeutic applications.

\section{Vaccines}

The immune system formed during long-term evolution can efficiently recognize and eliminate pathogens, such as viruses, through producing pathogen-specific immune response. From this point of view, many viral features, such as size, geometry, highly ordered and repeat structure, and multivalent display, which are critical for eliciting immune response, can be used to guide vaccine design (Bachmann and Jennings, 2010; Zepp, 2010). Phages are natural viruses that only infect bacteria, but have similar properties as mammalian viruses, and therefore can efficiently stimulate immune response (Jonczyk-Matysiak et al., 2017). Therefore, they have the high potentiality to be used as scaffolds to develop broadly applicable vaccine platforms (Fehr et al., 1998; Tissot et al., 2010; Nicastro et al., 2014; Henry et al., 2015; Fu and Li, 2016; Tao et al., 2018c). So far, many efforts have been focused on this topic, and many vaccine platforms have been developed using different phages, such as filamentous phages (Henry et al., 2015), phages $\lambda$ (Nicastro et al., 2014), T4 (Tao et al., 2013a,b), T7 (Danner and Belasco, 2001), MS2 (Fu and Li, 2016), Q $\beta$ (Fehr et al., 1998), and others (Tissot et al., 2010).

The basic principle using phage as antigen delivery vehicles involves assembly of the pathogen antigen on phage capsid either in vivo or in vitro to form a virus-like particle (VLP) through fusion of antigen to a virus capsid protein. The antigens, therefore, are presented on capsid surface in a highly ordered and repetitive format, which is critical for activation of innate immune systems (Shepardson et al., 2017). For in vivo assembly, the antigen gene has to be inserted into phage genome to form a fusion gene of antigen and capsid protein. For phages with small genomes, it is relatively easy to generate such mutant phages. However, for complex phages such as T4, this could 
be labor intensive and time consuming. Thanks to recent progresses on genome engineering technology, such as the CRISPR-Cas system, there is now no fundamental obstacles to engineering such phages.

Due to viral characters and its CpG (a ligand for Toll-like receptor 9)-containing genome DNA, phages are able to stimulate innate immune and therefore potentially act as a natural adjuvant (Zimecki et al., 2003; Kaur et al., 2012; Sartorius et al., 2015). Therefore, it might be that the display of antigens on phages links the antigen to a self-adjuvanting vaccine delivery system, which might elicit robust immune responses without any external adjuvants. Indeed, our studies indicated that antigens assembled on T4 capsid elicited stronger immune responses compared to their soluble counterparts (Tao et al., 2013a, 2018a). Furthermore, loading antigens on a self-adjuvanting delivery system allows the simultaneous delivery of both the components to the same immune cells such as antigenpresenting cells (APCs), which could significantly enhance the immune responses. For example, significant higher level of antigen-specific IgG antibodies was induced when displayed on phage $\mathrm{Q} \beta$ VLPs packaged with CpG than that of a simple mixture of antigen and CpG-packaged Q $\beta$ VLPs (Gomes et al., 2017).

Furthermore, presenting antigens on phage capsid surface in a highly ordered and repetitive format facilitates the binding of IgM to antigen epitope. For example, phage $\mathrm{Q} \beta$ capsid could bind to natural IgM and fix complement component $1 \mathrm{q}$ and therefore efficiently deposit on follicular dendritic cells (FDCs) (Link et al., 2012), which is essential for the selection of B cell during germinal center reactions (Baschong et al., 2003; Hinton et al., 2008). However, the soluble capsid protein failed to activate this humoral innate immune response and cannot efficiently deposit on FDCs (Link et al., 2012).

Another advantage of the phage VLPs is that they are particulate antigens with highly localized epitope density on the surface, which can be presented by both class I and class II major histocompatibility complex (MHC) and therefore activate both CD4+ and CD8+ T cells (Mantegazza et al., 2013). Assembly of antigen proteins on phage capsids forms a VLP vaccine, therefore, efficiently activating CD4+ and CD8+ $\mathrm{T}$ cells. Indeed, our study showed that HIV-1 p24 antigens assembled on T4 capsid were able to induce p24-specific CD8+ $\mathrm{T}$ cells in immunized mice. In contrast, soluble p24 protein elicited significantly lower or no p24-specific CD8+ T cells (Sathaliyawala et al., 2006). Similarly, F1mutV antigen of Yersinia pestis activated both type 1 and type 2 helper T cells in mice when assembled on T4 capsid, whereas soluble F1mutV antigen mainly activated type 2 helper $\mathrm{T}$ cells (Tao et al., 2013a, 2018a).

Since phage capsids are usually composed of hundreds of capsid protein(s) (Nicastro et al., 2014; Chen et al., 2017; Tao et al., 2018c), assembly of antigens on a phage capsid will result in highly localized epitope density, which was seen in most of the licensed viral vaccines (Cheng, 2016). The highly localized epitope density was suggested to facilitate B cell activation through promoting cross-linking of the $\mathrm{B}$ cell receptors to antigens (Bachmann et al., 1993; Bachmann and Zinkernagel,
1996). Indeed, the study using $Q \beta$ phage capsid indicated that a high density of a model peptide (D2) induced higher titers of D2-specific IgG than medium or low density (Jegerlehner et al., 2002). Targeting of antigens to immune cells is considered to be one of the promising strategies to enhance vaccine efficacy (Kastenmuller et al., 2014; Macri et al., 2016). The dendritic cells (DCs) are the most popular target immune cells due to its key roles in connecting innate and adaptive immune response (Steinman and Banchereau, 2007). Since there is no mammalian tropism, phages can be engineered to target to DCs through displaying a DC-specific targeting molecule and, therefore, enhancing the immune response against the delivered antigens. For instance, the phage fd was engineered to display a singlechain variable fragment (scFV) of antibody against a DC-specific receptor (DEC-205) and an ovalbumin peptide through pIII and pVIII capsid protein, respectively (Sartorius et al., 2015). When injected into mice, the resulted phages induced higher level antibody titers compared to the phages that only display ovalbumin peptide but lack targeting molecule (Sartorius et al., 2011). Most phages have more than one structural protein that can be used to display and, therefore, are able to link the antigen and the DC-targeting molecule to the same VLP. For example, we have shown that the two nonessential capsid proteins, $\mathrm{Hoc}$ and $\mathrm{Soc}$, of phage $\mathrm{T} 4$ can be used to simultaneously display two different foreign proteins (Li et al., 2007; Shivachandra et al., 2007; Tao et al., 2017a), one an antigen and another a DC-targeting molecule (e.g., a monoclonal antibody against DEC-205) (Tao et al., 2013b).

Although phages have many advantages as described above, to date, no vaccines employing a phage platform have yet been commercialized. Several phage platform-based vaccine candidates are undergoing clinical trials (Low et al., 2014; Huang et al., 2017), but most of these are still restricted to basic research. One reason could be that most of phages are not able to display the antigen in a high density as a full antigen, which is required for inducing high titers of conformation-specific neutralizing antibodies (Li et al., 2014). Additionally, pathogens can easily mutate certain key amino acids in the epitopes, making peptide vaccines based on one or a few epitopes less effective. However, recent progress on T4 phage platform showed that it is possible to display fulllength antigen at high density. For instance, up to 360 copies of $83 \mathrm{kDa}$ protective antigen (PA) (Li et al., 2007; Tao et al., 2018a), 350 copies of $90 \mathrm{kDa}$ lethal factor (LF) (Li et al., 2007), 650 copies of $66 \mathrm{kDa}$ plague F1mutV (Tao et al., 2013a, 2018a), and 200 copies of tetrameric $129 \mathrm{kDa} \beta$-galactosidase (Tao et al., 2013b) can be displayed on T4 capsid individually. Additionally, T4 phage platform can display antigens in vitro by incubating the purified Soc-antigen fusion proteins with purified Hoc $^{-}$Soc $^{-}$T4 phage (Tao et al., 2017a), which is critical for the display of conformation-sensitive proteins such as flu HA trimer and HIV gp140 trimer. Due to the absence of post-translational modification pathways in bacteria, phages cannot be used to in vivo display antigens that require posttranslation modifications, such as glycosylation that is important for structural and conformational integrity of the protein. 
As natural protein nanoparticles, phages are able to elicit immune responses (Dabrowska et al., 2014), thus potentially limiting their use when multiple vaccinations are needed. However, with recent progress on phage engineering, as discussed above, this can be minimized. The epitope regions of phage capsid proteins, like any other pathogen, have variable immunogenicity, and the epitope that elicits the most robust immune response is called immunodominant epitope (Akram and Inman, 2012). Therefore, the immunogenicity of phages can be reduced by disrupting the immunodominant epitopes through phage engineering. Second, attachment of polyethylene Glycol (PEG), also known as PEGylation, allows enhanced solubility as well as a reduction in the renal clearance hence, extending time in circulation (Suk et al., 2016).

\section{Phage Therapies}

Phages were used to treat bacterial infections since their discovery in the early 20th century ( $\mathrm{Lu}$ and Koeris, 2011; Wittebole et al., 2014; Moelling et al., 2018). Although discontinued in Western countries since the discovery of antibiotics in the 1940s (Moelling et al., 2018), the phage therapy was recently suggested by NIH as one of the seven innovative approaches to antimicrobial resistance research (National Institute of Allergy and Infectious Diseases, 2014). About 100 years of clinical usage of phage therapy in some Eastern European countries indicates that it could be a promising approach, particularly now that approaches for discovery of new broad spectrum antibiotics have nearly been exhausted (Moelling et al., 2018). In the past several years, we have isolated many phages from different bacterial hosts and showed their application to treat bacterial infection in animal models (Chen et al., 2018a,b,c, 2019a,b). Here, we are not going to much detail of phage therapy, but discuss the unique properties of phages that make them a promising alternative or supplement of antibiotics to treat bacterial pathogens. Phage engineering provides a rapid strategy to generate phage variants with unique properties, which might accelerate the development of phage therapy. For more detail of clinical application of phage therapy and related regulator obstacles, we encourage the reader to refer to the recent review articles (Kutter et al., 2010; Miedzybrodzki et al., 2012; Carvalho et al., 2017; Expert Round Table on Acceptance and Re-Implementation of Bacteriophage Therapy et al., 2018; Pirnay et al., 2018; Svircev et al., 2018; Kortright et al., 2019).

Unlike antibiotics or other chemical medicines, phages are natural organisms that can replicate in their host bacteria. This makes them an ideal weapon to fight against bacterial infections. In theory, a relatively small number of phages deposited at the site of infection are enough to treat a bacterial infection because of their replication and self-amplification. Once the pathogen was eliminated, phages no longer replicate and can be quickly cleared by the immune system or other mechanisms. For example, when phage MR-10 ( $\left.10^{8} \mathrm{PFU} / \mathrm{ml}\right)$ was injected into the hind paw of mice pre-infected by Staphylococcus aureus $\left(10^{6} \mathrm{CFU} / \mathrm{ml}\right)$, phage titers initially increased on days 1 and 3 but declined on day 5. The time course correlated very well with the clearance of $S$. aureus
(Chhibber et al., 2013). Secondly, the phages evolve with the selection condition, which helps them overcome bacterial resistance mechanisms. For instance, bacteria employ restrictionmodification (R-M) systems to destroy invading DNA, while keeping the self-DNA safe by methylation of specific sites (Samson et al., 2013; Seed, 2015). However, phages can incorporate base modification systems to keep their genome resistant to the bacterial R-M systems (Samson et al., 2013). For example, T4 phage modifies the cytosines by two modifications, 5-hydroxymethylation and glucosylation, which make it highly resistant to virtually all the restriction endonucleases of E. coli (Bryson et al., 2015). Bacterial CRISPR-Cas immune system is another well-studied anti-phage mechanism that protects the host through cleavage of phage DNA (Hille et al., 2018). Phages can evade CRISPR-Cas through either mutation of key nucleotides responsible for CRISPR-Cas complex binding/cleavage (Tao et al., 2018b) or expressing anti-CRISPR proteins (Pawluk et al., 2018). Modulating the availability of the receptors is another common mechanism employed by bacteria to block phage infection (Seed, 2015). However, phages can regain the ability of binding to their receptor by modifying the receptor-binding protein to adsorb to the evolving bacterial populations (Samson et al., 2013). Therefore, the endless coevolution of phages and their host bacteria makes bacteria less resistant to phage therapy than the antibiotic treatment, especially when phage cocktails are used.

Phages have high host specificity. Typically, a single type of phage can only recognize a limited range of bacterial strains (Nobrega et al., 2018). Therefore, they can be used to treat a specific bacterial pathogen without causing damage to the otherwise normal microbial community of the host. However, the narrow host range makes it almost impossible to target all strains within a given species using a single phage type. Thus, phage therapy requires the identification of pathogenic strain followed by the selection of effective phages, which will delay the treatment. However, there are ways to overcome this limitation (De Jonge et al., 2019). First, the host range of phages can be expanded or changed by genetic engineering techniques discussed above to manipulate the receptor-binding proteins. Swapping the receptor-binding protein genes between different types of phages, which have a different host, was able to change host specificity. For instance, replacing the long tail fiber genes of T2 phage with those from phage PP01 shifted the host of T2 from E. coli-K12 to E. coli O157:H7 (Yoichi et al., 2005). Similarly, replacing the long tail fiber genes with those from phage IP008, which has wide host range (can infect more E. coli strains), shifted the host range of T2 phage as that of IP008 (Mahichi et al., 2009). Swapping receptor-binding protein genes between more distant phages could even enable an engineered $E$. coli phage to infect Klebsiella bacteria and vice versa (Ando et al., 2015). The host range of phage can also be expanded by incorporation of a heterologous receptor binding domain (Marzari et al., 1997). For instance, filamentous phage fd infects E. coli bearing $\mathrm{F}$ pili, whereas filamentous IKe infects $E$. coli containing $\mathrm{N}$ or I pili. Fusion of the receptor-binding domain of IKe gene 
3 protein (pIII) to the $\mathrm{N}$ terminus of the fd pIII expanded the host range of fd phage (Marzari et al., 1997). The modified fd phage is able to infect $E$. coli bearing either $\mathrm{N}$ or $\mathrm{F}$ pili. Strikingly, fd was engineered to infect $V$. cholerae by adding the N-terminal 274 amino acids of pIII from filamentous phage CTXphi, which infects $V$. cholerae by toxin-coregulated pili, to the $\mathrm{N}$ terminus of the fd pIII (Heilpern and Waldor, 2003). Secondly, multiple phages targeting different strains can be isolated from natural environment to target more strains. A good example is the recent case of the "San Diego patient," who was infected with a multi-drug resistant $A$. baumannii strain and recovered after intravenous injection of phage cocktails (Schooley et al., 2017). However, this was no control here to assess if the therapeutic effect was entirely due to treatment with the phage cocktail. After screening more than 100 different phages isolated from environments, 9 phages that can lytic the patient's A. baumannii strain were selected to form three cocktails to treat the infection (Schooley et al., 2017). A number of phages targeting different Pasteurella multocida strains have been isolated (Chen et al., 2018b,c, 2019a), and the therapeutic effect of the phage cocktail is under investigation. Alternatively, phage-derived enzymes, such as virion-associated lysins, endolysin, and depolymerase, can be used to lyse bacteria (Maciejewska et al., 2018). For example, we showed that the depolymerase of phage $\mathrm{PHB} 02$, when was inoculated intraperitoneally, significantly increased the survival of mice pre-infected with P. multocida (Chen et al., 2018c). Although some of phage-derived enzymes also have narrow specificity, they are able to lysis a given bacterial specie other than a single strain (Maciejewska et al., 2018).

The most attractiveness of phages therapy is that it can be used to eliminate drug-resistant bacteria (Viertel et al., 2014). Phages and antibiotics have an intrinsic difference in their mechanisms of killing bacterial pathogens, and thus, there is no cross-resistance to antibiotics and phages. Technically, phages have the same efficiency to lyse antibiotic resistant bacteria as that of the antibiotic sensitive ones. Furthermore, phages and antibiotics can be combined to treat a bacterial infection (Torres-Barcelo and Hochberg, 2016). For instance, Kirby's study indicated that the combined use of gentamicin and phage (SA5) can be more efficacious than single therapies using either gentamicin or phage SA5 to treat Staphylococcus aureus. (Kirby, 2012). Similarly, combining phage LUZ7 and streptomycin decreased the titer of Pseudomonas aeruginosa compared to either treatment separately (Torres-Barcelo et al., 2014). This is also true in a diabetic mouse model, in which the hind paw of each mouse was infected with $S$. aureus (Chhibber et al., 2013). The maximum reduction of bacterial titer was obtained when phage MR-10 and linezolid were simultaneously used to treat the infection (Chhibber et al., 2013). The phage-antibiotic combinations not only enhance the eradication of bacteria but also prevent the emergence of resistant variants, compared to treatment with either phage or antibiotic alone. For instance, Verma et al. showed that the combination treatment using ciprofloxacin and phage KPO1K2 can not only eradicate the Klebsiella pneumoniae biofilm but also significantly arrest the emergence of resistant variants in vitro (Verma et al., 2009). Recent findings from Turner's group provided one of the mechanisms that phage infection might affect drug resistance of its host bacteria through evolutionary tradeoff between phage resistance and antibiotic resistance (Chan et al., 2016, 2018). They isolated a lytic phage, OMKO1, which infects Pseudomonas aeruginosa using the outer membrane porin $\mathrm{M}(\mathrm{OprM})$ as a receptor. OprM channel is a part of the antibiotic efflux pump of $P$. aeruginosa. Infection of phage OMKO1 led to selection of OprM mutations that affected its efflux function and restored antibiotic sensitivity of $P$. aeruginosa. Recent studies found that combination treatment using phage and sub-lethal concentrations of certain antibiotics would increase host bacterial production of phages, which was called phage-antibiotic synergy (PAS) phenomenon (Comeau et al., 2007; Kamal and Dennis, 2015). For instance, the production of phage $\Phi M F P$ in an uropathogenic E. coli strain increased more than sevenfold when $20 \mathrm{ng} / \mathrm{ml}$ cefotaxime was added to the medium (Comeau et al., 2007). This is also true in case of phage KS12, which infects Burkholderia cenocepacia strain K56-2 (Kamal and Dennis, 2015). The diameter of phage KS12 plaque increased from 1.22 to $2.37 \mathrm{~mm}$ when $4 \mathrm{X}$ the minimum inhibitory concentration of meropenem was added to the medium (Kamal and Dennis, 2015). In vivo experiments also showed that treatment with a combination of phage KS12 and $6 \mu \mathrm{g} / \mathrm{ml}$ meropenem increased the survival of Galleria mellonella larvae pre-infected with 9 LD50 (50\% lethal dose) of B. cenocepacia K56-2 compared to controls treated with KS12 or antibiotic alone (Kamal and Dennis, 2015).

Other than having direct antimicrobial activity, phages can be easily engineered using genetic engineering approaches to carry genes, proteins, or antimicrobial chemicals to enhance their antimicrobial activity. One good example is the delivery of biofilm-degrading enzyme dispersin B (DspB) using an engineered T7 phage (Lu and Collins, 2007). A biofilm is a structured community of microorganisms producing a polymeric matrix, which might make bacteria resistant to antimicrobial agents such as antibiotics and phages. The engineered phage T7 expressed $D s p B$ gene of Actinobacillus actinomycetemcomitans derived by T7 $\varphi 10$ promoter, which can be recognized by T7 RNA polymerase, therefore can significantly reduce bacterial count in a single-species E. coli biofilm than the T7 phage control did (Lu and Collins, 2007). Similarly, T7 phage was engineered to express a lactonase enzyme that interfered with the quorum sensing, which plays important role on biofilm formation. The resulted T7 phage reduced the biofilm formation by 74.9 and $65.9 \%$ at 4 and $8 \mathrm{~h}$ post-plating, respectively, compared to no-phage control. However, the wild-type T7 phage reduced only 23.8 and $31.7 \%$ at 4 and 8 h, respectively (Pei and Lamas-Samanamud, 2014). Other than delivering genes targeting biofilms, phages were also used to deliver an antibiotic drug or a CRISPR-Cas system (Bikard et al., 2014; Citorik et al., 2014) that is programmed to cleave a specific gene such as the antibiotic resistance genes. For instance, phagemids encoding the CRISPR-Cas9 system, which was programmed to target the aph-3 kanamycin resistance gene, was packaged in the Staphylococcal phage ФNM1 (Bikard et al., 2014). When 
S. aureus RN4220 cells carrying a kanamycin resistance gene were infected with the recombinant $\Phi$ NM1phage, strong inhibition of bacterial growth was observed. Conversely, the ФNM1phage packaged with non-targeting CRISPR-Cas system did not produce significant inhibition.

Although phage therapy has been used to prevent or treat bacterial infection for almost 100 years particularly in Eastern European counties such as Georgia, it has not been well accepted in Western countries. One reason is the lack of detail information on the early clinical trials or applications. No details on the experiment design or data analysis were provided, although some of the clinical data were available in their internal publications (Kutter et al., 2010). The first placebo-controlled, double-blind clinical trials were published in 2009 targeting to drug-resistant $P$. aeruginosa, which causes chronic otitis (Wright et al., 2009). This study showed encouraging results in that phage treatment resulted in significant clinical improvement compared to placebo controls. Since then, 14 clinical trials have been launched or completely carried out (Expert Round Table on Acceptance and Re-Implementation of Bacteriophage Therapy et al., 2018). However, most of these clinical results have not published yet, which are needed to further evaluate the potential of phages in treating bacterial infections (Expert Round Table on Acceptance and Re-Implementation of Bacteriophage Therapy et al., 2018). For more detail from clinical aspect of phage therapy, we encourage the reader to refer to the recent elegant review articles (Kutter et al., 2010; Miedzybrodzki et al., 2012). Another challenge of phage therapy is government regulatory hurdles especially in Western countries. Phages were classified as drugs and medicinal products in United States and European Union, respectively (Pirnay et al., 2018). Therefore, it requires strict clinical trials and complicated drug approval procedures before reaching market. However, the recent pragmatic phage therapy framework that centers on the "magistral preparation" of tailormade phage medicines in Belgium might provide a light for future clinical application of phages (Pirnay et al., 2018).

\section{REFERENCES}

Akram, A., and Inman, R. D. (2012). Immunodominance: a pivotal principle in host response to viral infections. Clin. Immunol. 143, 99-115. doi: 10.1016/j. clim.2012.01.015

Ando, H., Lemire, S., Pires, D. P., and Lu, T. K. (2015). Engineering modular viral scaffolds for targeted bacterial population editing. Cell Syst. 1, 187-196. doi: 10.1016/j.cels.2015.08.013

Bachmann, M. F., and Jennings, G. T. (2010). Vaccine delivery: a matter of size, geometry, kinetics and molecular patterns. Nat. Rev. Immunol. 10, 787-796. doi: $10.1038 /$ nri2868

Bachmann, M. F., Rohrer, U. H., Kundig, T. M., Burki, K., Hengartner, H., and Zinkernagel, R. M. (1993). The influence of antigen organization on B cell responsiveness. Science 262, 1448-1451. doi: 10.1126/ science. 8248784

Bachmann, M. F., and Zinkernagel, R. M. (1996). The influence of virus structure on antibody responses and virus serotype formation. Immunol. Today 17, 553-558. doi: 10.1016/S0167-5699(96)10066-9

Bardy, P., Pantucek, R., Benesik, M., and Doskar, J. (2016). Genetically modified bacteriophages in applied microbiology. J. Appl. Microbiol. 121, 618-633. doi: $10.1111 /$ jam.13207

\section{CONCLUSIONS}

The emergence of multi-antibiotic resistant bacterial pathogens and their continuing spread in the population brought new urgency to develop alternative strategies to treat bacterial infections. Phage therapy and phage nanoparticle vaccination could be two promising strategies to address this crisis. Successful treatment of the "San Diego patient" and several ongoing phage therapy clinical trials demonstrate the potential of this approach to develop phage antibiotics (Schooley et al., 2017; Expert Round Table on Acceptance and Re-Implementation of Bacteriophage Therapy et al., 2018). Phage VLP vaccines have shown high efficacy in the animal models, and some have already entered clinical trials (Huang et al., 2017; Tao et al., 2018c). There are however limitations to the naturally occurring phages but, fortunately, recent progress in phage genome engineering promises to overcome these limits, such as expanding phage host range to facilitate phage therapy and disrupting the immunodominant epitope of phage capsid to eliminate immune response against phage and, therefore, to generate precise variants against infectious diseases (Nobrega et al., 2015; Bardy et al., 2016; Pires et al., 2016; Kilcher and Loessner, 2019).

\section{AUTHOR CONTRIBUTIONS}

YC, HB, JD, CC, and PT wrote the manuscript. VR and PT edited the manuscript.

\section{FUNDING}

Our researches are supported by grants from the National Institute of Allergy and Infectious Diseases (current: AI111538 and AI081726), Fundamental Research Funds for the Central Universities (Program No. 2662019PY002), and the National Natural Science Foundation of China (Grant No. 31870915).

Bari, S. M. N., Walker, F. C., Cater, K., Aslan, B., and Hatoum-Aslan, A (2017). Strategies for editing virulent staphylococcal phages using CRISPRCas10. ACS Synth. Biol. 6, 2316-2325. doi: 10.1021/acssynbio.7b00240

Barrangou, R., Fremaux, C., Deveau, H., Richards, M., Boyaval, P., Moineau, S., et al. (2007). CRISPR provides acquired resistance against viruses in prokaryotes. Science 315, 1709-1712. doi: 10.1126/science.1138140

Baschong, W., Hasler, L., Haner, M., Kistler, J., and Aebi, U. (2003). Repetitive versus monomeric antigen presentation: direct visualization of antibody affinity and specificity. J. Struct. Biol. 143, 258-262. doi: 10.1016/j. jsb.2003.08.004

Bergh, O., Borsheim, K. Y., Bratbak, G., and Heldal, M. (1989). High abundance of viruses found in aquatic environments. Nature 340, 467-468. doi: 10.1038/340467a0

Bikard, D., Euler, C. W., Jiang, W., Nussenzweig, P. M., Goldberg, G. W., Duportet, X., et al. (2014). Exploiting CRISPR-Cas nucleases to produce sequence-specific antimicrobials. Nat. Biotechnol. 32, 1146-1150. doi: 10.1038/ nbt.3043

Box, A. M., Mcguffie, M. J., O'hara, B. J., and Seed, K. D. (2016). Functional analysis of bacteriophage immunity through a type I-E CRISPR-Cas system in Vibrio cholerae and its application in bacteriophage genome engineering. J. Bacteriol. 198, 578-590. doi: 10.1128/JB.00747-15 
Brissett, N. C., and Doherty, A. J. (2009). Repairing DNA double-strand breaks by the prokaryotic non-homologous end-joining pathway. Biochem. Soc. Trans. 37, 539-545. doi: 10.1042/BST0370539

Bryson, A. L., Hwang, Y., Sherrill-Mix, S., Wu, G. D., Lewis, J. D., Black, L., et al. (2015). Covalent modification of bacteriophage T4 DNA inhibits CRISPR-Cas9. MBio 6:e00648. doi: 10.1128/mBio.00648-15

Cao, B., Li, Y., Yang, T., Bao, Q., Yang, M., and Mao, C. (2018). Bacteriophagebased biomaterials for tissue regeneration. Adv. Drug Deliv. Rev. pii: S0169-409X(18)30291-6. doi: 10.1016/j.addr.2018.11.004

Cao, B., Yang, M., and Mao, C. (2016). Phage as a genetically modifiable supramacromolecule in chemistry, materials and medicine. Acc. Chem. Res. 49, 1111-1120. doi: 10.1021/acs.accounts.5b00557

Carvalho, C., Costa, A. R., Silva, F., and Oliveira, A. (2017). Bacteriophages and their derivatives for the treatment and control of food-producing animal infections. Crit. Rev. Microbiol. 43, 583-601. doi: 10.1080/1040841X.2016.1271309

Chan, L. Y., Kosuri, S., and Endy, D. (2005). Refactoring bacteriophage T7. Mol. Syst. Biol. 1:(1744-4292 (Electronic)):0018. doi: 10.1038/msb4100025

Chan, B. K., Sistrom, M., Wertz, J. E., Kortright, K. E., Narayan, D., and Turner, P. E. (2016). Phage selection restores antibiotic sensitivity in MDR Pseudomonas aeruginosa. Sci. Rep. 6:26717. doi: 10.1038/srep26717

Chan, B. K., Turner, P. E., Kim, S., Mojibian, H. R., Elefteriades, J. A., and Narayan, D. (2018). Phage treatment of an aortic graft infected with Pseudomonas aeruginosa. Evol. Med. Public Health 2018, 60-66. doi: 10.1093/emph/eoy005

Chanishvili, N. (2012). Phage therapy-history from Twort and d'Herelle through soviet experience to current approaches. Adv. Virus Res. 83, 3-40. doi: 10.1016/B978-0-12-394438-2.00001-3

Chanishvili, N. (2016). Bacteriophages as therapeutic and prophylactic means: summary of the soviet and post soviet experiences. Curr. Drug Deliv. 13, 309-323. doi: 10.2174/156720181303160520193946

Chen, Y., Guo, G., Sun, E., Song, J., Yang, L., Zhu, L., et al. (2019a). Isolation of a T7-like lytic pasteurella bacteriophage vB_PmuP_PHB01 and its potential use in therapy against Pasteurella multocida infections. Viruses 11, pii: E86. doi: $10.3390 / \mathrm{v} 11010086$

Chen, Y., Sun, E., Song, J., Tong, Y., and Wu, B. (2018a). Three Salmonella enterica serovar Enteritidis bacteriophages from the Siphoviridae family are promising candidates for phage therapy. Can. J. Microbiol. 64, 865-875. doi: 10.1139/cjm-2017-0740

Chen, Y., Sun, E., Song, J., Yang, L., and Wu, B. (2018b). Complete genome sequence of a novel T7-like bacteriophage from a Pasteurella multocida capsular type A isolate. Curr. Microbiol. 75, 574-579. doi: 10.1007/s00284-017-1419-3

Chen, Y., Sun, E., Yang, L., Song, J., and Wu, B. (2018c). Therapeutic application of bacteriophage PHBO2 and its putative depolymerase against Pasteurella multocida capsular type A in Mice. Front. Microbiol. 9:1678. doi: 10.3389/ fmicb.2018.01678

Chen, Z., Sun, L., Zhang, Z., Fokine, A., Padilla-Sanchez, V., Hanein, D., et al. (2017). Cryo-EM structure of the bacteriophage T4 isometric head at 3.3-A resolution and its relevance to the assembly of icosahedral viruses. Proc. Natl. Acad. Sci. USA 114, E8184-E8193. doi: 10.1073/pnas.1708483114

Chen, Y., Yang, L., Sun, E., Song, J., and Wu, B. (2019b). Characterisation of a newly detected bacteriophage infecting Bordetella bronchiseptica in swine. Arch. Virol. 164, 33-40. doi: 10.1007/s00705-018-4034-0

Cheng, W. (2016). The density code for the development of a vaccine? J. Pharm. Sci. 105, 3223-3232. doi: 10.1016/j.xphs.2016.07.020

Chhibber, S., Kaur, T., and Sandeep, K. (2013). Co-therapy using lytic bacteriophage and linezolid: effective treatment in eliminating methicillin resistant Staphylococcus aureus (MRSA) from diabetic foot infections. PLoS One 8:e56022. doi: 10.1371/journal.pone.0056022

Citorik, R. J., Mimee, M., and Lu, T. K. (2014). Sequence-specific antimicrobials using efficiently delivered RNA-guided nucleases. Nat. Biotechnol. 32, 1141-1145. doi: $10.1038 /$ nbt.3011

Comeau, A. M., Tetart, F., Trojet, S. N., Prere, M. F., and Krisch, H. M. (2007). Phage-antibiotic synergy (PAS): beta-lactam and quinolone antibiotics stimulate virulent phage growth. PLoS One 2:e799. doi: 10.1371/journal.pone.0000799

Dabrowska, K., Miernikiewicz, P., Piotrowicz, A., Hodyra, K., Owczarek, B., Lecion, D., et al. (2014). Immunogenicity studies of proteins forming the T4 phage head surface. J. Virol. 88, 12551-12557. doi: 10.1128/JVI.02043-14

Danner, S., and Belasco, J. G. (2001). T7 phage display: a novel genetic selection system for cloning RNA-binding proteins from cDNA libraries. Proc. Natl. Acad. Sci. USA 98, 12954-12959. doi: 10.1073/pnas.211439598
De Jonge, P. A., Nobrega, F. L., Brouns, S. J. J., and Dutilh, B. E. (2019). Molecular and evolutionary determinants of bacteriophage host range. Trends Microbiol. 27, 51-63. doi: 10.1016/j.tim.2018.08.006

Debarbieux, L., Leduc, D., Maura, D., Morello, E., Criscuolo, A., Grossi, O., et al. (2010). Bacteriophages can treat and prevent Pseudomonas aeruginosa lung infections. J. Infect. Dis. 201, 1096-1104. doi: 10.1086/651135

Domingo-Calap, P., and Delgado-Martinez, J. (2018). Bacteriophages: protagonists of a post-antibiotic era. Antibiotics (Basel) 7, pii: E66. doi: 10.3390/antibiotics7030066

Expert Round Table on Acceptance and Re-Implementation of Bacteriophage Therapy, Sybesma, W., Rohde, C., Bardy, P., Pirnay, J. P., Cooper, I., et al. (2018). Silk route to the acceptance and re-implementation of bacteriophage therapy-part II. Antibiotics (Basel) 7, pii: E35. doi: 10.3390/antibiotics7020035

Fehr, T., Skrastina, D., Pumpens, P., and Zinkernagel, R. M. (1998). T cellindependent type I antibody response against B cell epitopes expressed repetitively on recombinant virus particles. Proc. Natl. Acad. Sci. USA 95, 9477-9481.

Fineran, P. C., Gerritzen, M. J., Suarez-Diez, M., Kunne, T., Boekhorst, J., Van Hijum, S. A., et al. (2014). Degenerate target sites mediate rapid primed CRISPR adaptation. Proc. Natl. Acad. Sci. USA 111, E1629-E1638. doi: $10.1073 /$ pnas. 1400071111

$\mathrm{Fu}, \mathrm{Y}$., and Li, J. (2016). A novel delivery platform based on bacteriophage MS2 virus-like particles. Virus Res. 211, 9-16. doi: 10.1016/j.virusres.2015.08.022

Gomes, A. C., Flace, A., Saudan, P., Zabel, F., Cabral-Miranda, G., Turabi, A. E., et al. (2017). Adjusted particle size eliminates the need of linkage of antigen and adjuvants for appropriated $\mathrm{T}$ cell responses in virus-like particle-based vaccines. Front. Immunol. 8:226. doi: 10.3389/fimmu.2017.00226

Hatoum-Aslan, A. (2018). Phage genetic engineering using CRISPR-Cas systems. Viruses 10, pii: E335. doi: 10.3390/v10060335

Heilpern, A. J., and Waldor, M. K. (2003). pIIICTX, a predicted CTXphi minor coat protein, can expand the host range of coliphage fd to include Vibrio cholerae. J. Bacteriol. 185, 1037-1044. doi: 10.1128/JB.185.3.1037-1044.2003

Henry, K. A., Arbabi-Ghahroudi, M., and Scott, J. K. (2015). Beyond phage display: non-traditional applications of the filamentous bacteriophage as a vaccine carrier, therapeutic biologic, and bioconjugation scaffold. Front. Microbiol. 6:755. doi: 10.3389/fmicb.2015.00755

Hille, F., Richter, H., Wong, S. P., Bratovic, M., Ressel, S., and Charpentier, E. (2018). The biology of CRISPR-Cas: backward and forward. Cell 172, 1239-1259. doi: 10.1016/j.cell.2017.11.032

Hinton, H. J., Jegerlehner, A., and Bachmann, M. F. (2008). Pattern recognition by B cells: the role of antigen repetitiveness versus Toll-like receptors. Curr. Top. Microbiol. Immunol. 319, 1-15. doi: 10.1007/978-3-540-73900-5_1

Hou, Z., Zhou, Z., Wang, Z., and Xiao, G. (2016). Assembly of long DNA sequences using a new synthetic Escherichia coli-yeast shuttle vector. Virol. Sin. 31, 160-167. doi: 10.1007/s12250-016-3730-8

Huang, X., Wang, X., Zhang, J., Xia, N., and Zhao, Q. (2017). Escherichia coli-derived virus-like particles in vaccine development. NPJ Vaccines 2:3. doi: 10.1038/s41541-017-0006-8

Hupfeld, M., Trasanidou, D., Ramazzini, L., Klumpp, J., Loessner, M. J., and Kilcher, S. (2018). A functional type II-A CRISPR-Cas system from Listeria enables efficient genome editing of large non-integrating bacteriophage. Nucleic Acids Res. 46, 6920-6933. doi: 10.1093/nar/gky544

Jaschke, P. R., Lieberman, E. K., Rodriguez, J., Sierra, A., and Endy, D. (2012). A fully decompressed synthetic bacteriophage oX174 genome assembled and archived in yeast. Virology 434, 278-284. doi: 10.1016/j. virol.2012.09.020

Jegerlehner, A., Storni, T., Lipowsky, G., Schmid, M., Pumpens, P., and Bachmann, M. F. (2002). Regulation of IgG antibody responses by epitope density and CD21-mediated costimulation. Eur. J. Immunol. 32, 3305-3314. doi: 10.1002/1521-4141(200211)32:11<3305::AID-IMMU3305>3.0.CO;2-J

Jonczyk-Matysiak, E., Weber-Dabrowska, B., Owczarek, B., Miedzybrodzki, R., Lusiak-Szelachowska, M., Lodej, N., et al. (2017). Phage-phagocyte interactions and their implications for phage application as therapeutics. Viruses 9, pii: E150. doi: $10.3390 / \mathrm{v} 9060150$

Kamal, F., and Dennis, J. J. (2015). Burkholderia cepacia complex phage-antibiotic synergy (PAS): antibiotics stimulate lytic phage activity. Appl. Environ. Microbiol. 81, 1132-1138. doi: 10.1128/AEM.02850-14

Karam, J. D., Drake, J. W., Kreuzer, K. N., Mosig, G., Hall, D. H., Eiserling, F. A., et al. (1994). Molecular biology of bacteriophage T4. (Washington, DC: American Society for Microbiology). 
Kastenmuller, W., Kastenmuller, K., Kurts, C., and Seder, R. A. (2014). Dendritic cell-targeted vaccines-hope or hype? Nat. Rev. Immunol. 14, 705-711. doi: 10.1038/nri3727

Kaur, T., Nafissi, N., Wasfi, O., Sheldon, K., Wettig, S., and Slavcev, R. (2012). Immunocompatibility of bacteriophages as nanomedicines. J. Nanotechnol. 2012, 1-13. doi: 10.1155/2012/247427

Kilcher, S., and Loessner, M. J. (2019). Engineering bacteriophages as versatile biologics. Trends Microbiol. 27, 355-367. doi: 10.1016/j.tim.2018.09.006

Kilcher, S., Studer, P., Muessner, C., Klumpp, J., and Loessner, M. J. (2018). Crossgenus rebooting of custom-made, synthetic bacteriophage genomes in L-form bacteria. Proc. Natl. Acad. Sci. USA 115, 567-572. doi: 10.1073/pnas.1714658115

Kirby, A. E. (2012). Synergistic action of gentamicin and bacteriophage in a continuous culture population of Staphylococcus aureus. PLoS One 7:e51017. doi: 10.1371/journal.pone.0051017

Kiro, R., Shitrit, D., and Qimron, U. (2014). Efficient engineering of a bacteriophage genome using the type I-E CRISPR-Cas system. RNA Biol. 11, 42-44. doi: 10.4161/rna.27766

Knott, G. J., and Doudna, J. A. (2018). CRISPR-Cas guides the future of genetic engineering. Science 361, 866-869. doi: 10.1126/science.aat5011

Koonin, E. V., Makarova, K. S., and Zhang, F. (2017). Diversity, classification and evolution of CRISPR-Cas systems. Curr. Opin. Microbiol. 37, 67-78. doi: 10.1016/j.mib.2017.05.008

Kortright, K. E., Chan, B. K., Koff, J. L., and Turner, P. E. (2019). Phage therapy: a renewed approach to combat antibiotic-resistant bacteria. Cell Host Microbe 25, 219-232. doi: 10.1016/j.chom.2019.01.014

Kutter, E., De Vos, D., Gvasalia, G., Alavidze, Z., Gogokhia, L., Kuhl, S., et al. (2010). Phage therapy in clinical practice: treatment of human infections. Curr. Pharm. Biotechnol. 11, 69-86. doi: 10.2174/138920110790725401

Lemay, M. L., Tremblay, D. M., and Moineau, S. (2017). Genome engineering of virulent lactococcal phages using CRISPR-Cas9. ACS Synth. Biol. 6, 1351-1358. doi: 10.1021/acssynbio.6b00388

Lemire, S., Yehl, K. M., and Lu, T. K. (2018). Phage-based applications in synthetic biology. Annu. Rev. Virol. 5, 453-476. doi: 10.1146/annurevvirology-092917-043544

Li, W., Joshi, M. D., Singhania, S., Ramsey, K. H., and Murthy, A. K. (2014). Peptide vaccine: progress and challenges. Vaccines 2, 515-536. doi: 10.3390/ vaccines 2030515

Li, Q., Shivachandra, S. B., Zhang, Z., and Rao, V. B. (2007). Assembly of the small outer capsid protein, Soc, on bacteriophage T4: a novel system for high density display of multiple large anthrax toxins and foreign proteins on phage capsid. J. Mol. Biol. 370, 1006-1019. doi: 10.1016/j.jmb.2007.05.008

Link, A., Zabel, F., Schnetzler, Y., Titz, A., Brombacher, F., and Bachmann, M. F. (2012). Innate immunity mediates follicular transport of particulate but not soluble protein antigen. J. Immunol. 188, 3724-3733. doi: 10.4049/ jimmunol.1103312

Low, J. G., Lee, L. S., Ooi, E. E., Ethirajulu, K., Yeo, P., Matter, A., et al. (2014). Safety and immunogenicity of a virus-like particle pandemic influenza A (H1N1) 2009 vaccine: results from a double-blinded, randomized phase I clinical trial in healthy Asian volunteers. Vaccine 32, 5041-5048. doi: 10.1016/j.vaccine.2014.07.011

Lu, T. K., and Collins, J. J. (2007). Dispersing biofilms with engineered enzymatic bacteriophage. Proc. Natl. Acad. Sci. USA 104, 11197-11202. doi: 10.1073/ pnas.0704624104

Lu, T. K., and Koeris, M. S. (2011). The next generation of bacteriophage therapy. Curr. Opin. Microbiol. 14, 524-531. doi: 10.1016/j.mib.2011.07.028

Maciejewska, B., Olszak, T., and Drulis-Kawa, Z. (2018). Applications of bacteriophages versus phage enzymes to combat and cure bacterial infections: an ambitious and also a realistic application? Appl. Microbiol. Biotechnol. 102, 2563-2581. doi: 10.1007/s00253-018-8811-1

Macri, C., Dumont, C., Johnston, A. P., and Mintern, J. D. (2016). Targeting dendritic cells: a promising strategy to improve vaccine effectiveness. Clin. Transl. Immunol. 5:e66. doi: 10.1038/cti.2016.6

Mahichi, F., Synnott, A. J., Yamamichi, K., Osada, T., and Tanji, Y. (2009). Site-specific recombination of T2 phage using IP008 long tail fiber genes provides a targeted method for expanding host range while retaining lytic activity. FEMS Microbiol. Lett. 295, 211-217. doi: 10.1111/j. 1574-6968.2009.01588.x

Mamedov, T. G., Padhye, N. V., Viljoen, H., and Subramanian, A. (2007). Rational de novo gene synthesis by rapid polymerase chain assembly (PCA) and expression of endothelial protein-C and thrombin receptor genes. J. Biotechnol. 131, 379-387. doi: 10.1016/j.jbiotec.2007.08.010

Mantegazza, A. R., Magalhaes, J. G., Amigorena, S., and Marks, M. S. (2013). Presentation of phagocytosed antigens by MHC class I and II. Traffic 14, 135-152. doi: 10.1111/tra.12026

Marinelli, L. J., Hatfull, G. F., and Piuri, M. (2012). Recombineering: a powerful tool for modification of bacteriophage genomes. Bacteriophage 2, 5-14. doi: 10.4161/bact.18778

Marinelli, L. J., Piuri, M., Swigonova, Z., Balachandran, A., Oldfield, L. M., Van Kessel, J. C., et al. (2008). BRED: a simple and powerful tool for constructing mutant and recombinant bacteriophage genomes. PLoS One 3:e3957. doi: 10.1371/journal.pone.0003957

Martel, B., and Moineau, S. (2014). CRISPR-Cas: an efficient tool for genome engineering of virulent bacteriophages. Nucleic Acids Res. 42, 9504-9513. doi: $10.1093 /$ nar/gku628

Marzari, R., Sblattero, D., Righi, M., and Bradbury, A. (1997). Extending filamentous phage host range by the grafting of a heterologous receptor binding domain. Gene 185, 27-33. doi: 10.1016/S0378-1119(96)00623-3

Miedzybrodzki, R., Borysowski, J., Weber-Dabrowska, B., Fortuna, W., Letkiewicz, S., Szufnarowski, K., et al. (2012). Clinical aspects of phage therapy. Adv. Virus Res. 83, 73-121. doi: 10.1016/B978-0-12-394438-2.00003-7

Moelling, K., Broecker, F., and Willy, C. (2018). A wake-up call: we need phage therapy now. Viruses 10, pii: E688. doi: 10.3390/v10120688

Murphy, K. C. (2012). Phage recombinases and their applications. Adv. Virus Res. 83, 367-414. doi: 10.1016/B978-0-12-394438-2.00008-6

Nafissi, N., and Slavcev, R. (2014). Bacteriophage recombination systems and biotechnical applications. Appl. Microbiol. Biotechnol. 98, 2841-2851. doi: 10.1007/s00253-014-5512-2

Namura, M., Hijikata, T., Miyanaga, K., and Tanji, Y. (2008). Detection of Escherichia coli with fluorescent labeled phages that have a broad host range to E. coli in sewage water. Biotechnol. Prog. 24, 481-486. doi: 10.1021/bp070326c

National Institute of Allergy and Infectious Diseases (2014). NIAID's Antibacterial Resistance Program: Current Status and Future Directions. National Institutes of Health-USA. https://www.niaid.nih.gov/sites/default/files/arstrategicplan2014.pdf

Nicastro, J., Sheldon, K., and Slavcev, R. A. (2014). Bacteriophage lambda display systems: developments and applications. Appl. Microbiol. Biotechnol. 98, 2853-2866. doi: 10.1007/s00253-014-5521-1

Nobrega, F. L., Costa, A. R., Kluskens, L. D., and Azeredo, J. (2015). Revisiting phage therapy: new applications for old resources. Trends Microbiol. 23, 185-191. doi: 10.1016/j.tim.2015.01.006

Nobrega, F. L., Vlot, M., De Jonge, P. A., Dreesens, L. L., Beaumont, H. J. E., Lavigne, R., et al. (2018). Targeting mechanisms of tailed bacteriophages. Nat. Rev. Microbiol. 16, 760-773. doi: 10.1038/s41579-018-0070-8

Oda, M., Morita, M., Unno, H., and Tanji, Y. (2004). Rapid detection of Escherichia coli O157:H7 by using green fluorescent protein-labeled PP01 bacteriophage. Appl. Environ. Microbiol. 70, 527-534. doi: 10.1128/ AEM.70.1.527-534.2004

Oppenheim, A. B., Rattray, A. J., Bubunenko, M., Thomason, L. C., and Court, D. L. (2004). In vivo recombineering of bacteriophage lambda by PCR fragments and single-strand oligonucleotides. Virology 319, 185-189. doi: 10.1016/j.virol.2003.11.007

Pan, Y. J., Lin, T. L., Chen, C. C., Tsai, Y. T., Cheng, Y. H., Chen, Y. Y., et al. (2017). Klebsiella phage PhiK64-1 encodes multiple depolymerases for multiple host capsular types. J. Virol. 91, pii: e02457-16. doi: 10.1128/JVI.02457-16

Pawluk, A., Davidson, A. R., and Maxwell, K. L. (2018). Anti-CRISPR: discovery, mechanism and function. Nat. Rev. Microbiol. 16, 12-17. doi: 10.1038/ nrmicro.2017.120

Pei, R., and Lamas-Samanamud, G. R. (2014). Inhibition of biofilm formation by $\mathrm{T} 7$ bacteriophages producing quorum-quenching enzymes. Appl. Environ. Microbiol. 80, 5340-5348. doi: 10.1128/AEM.01434-14

Pires, D. P., Cleto, S., Sillankorva, S., Azeredo, J., and Lu, T. K. (2016). Genetically engineered phages: a review of advances over the last decade. Microbiol. Mol. Biol. Rev. 80, 523-543. doi: 10.1128/MMBR.00069-15

Pirnay, J. P., Verbeken, G., Ceyssens, P. J., Huys, I., De Vos, D., Ameloot, C., et al. (2018). The magistral phage. Viruses 10, pii: E64. doi: 10.3390/ v10020064

Poteete, A. R. (2001). What makes the bacteriophage lambda red system useful for genetic engineering: molecular mechanism and biological function. FEMS Microbiol. Lett. 201, 9-14. doi: 10.1111/j.1574-6968.2001.tb10725.x 
Rao, V. B., and Mitchell, M. S. (2001). The N-terminal ATPase site in the large terminase protein gp17 is critically required for DNA packaging in bacteriophage T4. J. Mol. Biol. 314, 401-411. doi: 10.1006/ jmbi.2001.5169

Salmond, G. P., and Fineran, P. C. (2015). A century of the phage: past, present and future. Nat. Rev. Microbiol. 13, 777-786. doi: 10.1038/nrmicro3564

Samson, J. E., Magadan, A. H., Sabri, M., and Moineau, S. (2013). Revenge of the phages: defeating bacterial defences. Nat. Rev. Microbiol. 11, 675-687. doi: $10.1038 /$ nrmicro3096

Sarkis, G. J., Jacobs, W. R. Jr., and Hatfull, G. F. (1995). L5 luciferase reporter mycobacteriophages: a sensitive tool for the detection and assay of live mycobacteria. Mol. Microbiol. 15, 1055-1067. doi: 10.1111/j.1365-2958.1995. tb02281.x

Sartorius, R., Bettua, C., D’apice, L., Caivano, A., Trovato, M., Russo, D., et al. (2011). Vaccination with filamentous bacteriophages targeting DEC-205 induces DC maturation and potent anti-tumor T-cell responses in the absence of adjuvants. Eur. J. Immunol. 41, 2573-2584. doi: 10.1002/eji.201141526

Sartorius, R., D’apice, L., Trovato, M., Cuccaro, F., Costa, V., De Leo, M. G., et al. (2015). Antigen delivery by filamentous bacteriophage fd displaying an anti-DEC-205 single-chain variable fragment confers adjuvanticity by triggering a TLR9-mediated immune response. EMBO Mol. Med. 7, 973-988. doi: 10.15252/emmm.201404525

Sathaliyawala, T., Rao, M., Maclean, D. M., Birx, D. L., Alving, C. R., and Rao, V. B. (2006). Assembly of human immunodeficiency virus (HIV) antigens on bacteriophage T4: a novel in vitro approach to construct multicomponent HIV vaccines. J. Virol. 80, 7688-7698. doi: 10.1128/JVI.00235-06

Schilling, T., Dietrich, S., Hoppert, M., and Hertel, R. (2018). A CRISPR-Cas9based toolkit for fast and precise in vivo genetic engineering of Bacillus subtilis phages. Viruses 10, pii: E241. doi: 10.3390/v10050241

Schooley, R. T., Biswas, B., Gill, J. J., Hernandez-Morales, A., Lancaster, J., Lessor, L., et al. (2017). Development and use of personalized bacteriophagebased therapeutic cocktails to treat a patient with a disseminated resistant Acinetobacter baumannii infection. Antimicrob. Agents Chemother. 61, pii: e00954-17. doi: 10.1128/AAC.00954-17

Seed, K. D. (2015). Battling phages: how bacteria defend against viral attack. PLoS Pathog. 11:e1004847. doi: 10.1371/journal.ppat.1004847

Shang, Y., Wang, M., Xiao, G., Wang, X., Hou, D., Pan, K., et al. (2017). Construction and rescue of a functional synthetic baculovirus. ACS Synth. Biol. 6, 1393-1402. doi: 10.1021/acssynbio.7b00028

Shen, J., Zhou, J., Chen, G. Q., and Xiu, Z. L. (2018). Efficient genome engineering of a virulent klebsiella bacteriophage using CRISPR-Cas9. J. Virol. 92, pii: e00534-18. doi: 10.1128/JVI.00534-18

Shepardson, K. M., Schwarz, B., Larson, K., Morton, R. V., Avera, J., Mccoy, K., et al. (2017). Induction of antiviral immune response through recognition of the repeating subunit pattern of viral capsids is toll-like receptor 2 dependent. MBio 8, pii: e01356-17. doi: 10.1128/mBio.01356-17

Shivachandra, S. B., Li, Q., Peachman, K. K., Matyas, G. R., Leppla, S. H., Alving, C. R., et al. (2007). Multicomponent anthrax toxin display and delivery using bacteriophage T4. Vaccine 25, 1225-1235. doi: 10.1016/j. vaccine.2006.10.010

Shmakov, S., Smargon, A., Scott, D., Cox, D., Pyzocha, N., Yan, W., et al. (2017). Diversity and evolution of class 2 CRISPR-Cas systems. Nat. Rev. Microbiol. 15, 169-182. doi: 10.1038/nrmicro.2016.184

Smith, H. O., Hutchison, C. A. III, Pfannkoch, C., and Venter, J. C. (2003). Generating a synthetic genome by whole genome assembly: phiX174 bacteriophage from synthetic oligonucleotides. Proc. Natl. Acad. Sci. USA 100, 15440-15445. doi: 10.1073/pnas.2237126100

Steinman, R. M., and Banchereau, J. (2007). Taking dendritic cells into medicine. Nature 449, 419-426. doi: 10.1038/nature06175

Suk, J. S., Xu, Q., Kim, N., Hanes, J., and Ensign, L. M. (2016). PEGylation as a strategy for improving nanoparticle-based drug and gene delivery. Adv. Drug Deliv. Rev. 99, 28-51. doi: 10.1016/j.addr.2015.09.012

Svircev, A., Roach, D., and Castle, A. (2018). Framing the future with bacteriophages in agriculture. Viruses 10, pii: E218. doi: 10.3390/v10050218

Tanji, Y., Furukawa, C., Na, S. H., Hijikata, T., Miyanaga, K., and Unno, H. (2004). Escherichia coli detection by GFP-labeled lysozyme-inactivated T4 bacteriophage. J. Biotechnol. 114, 11-20. doi: 10.1016/j.jbiotec.2004.05.011

Tao, P., Li, Q., Shivachandra, S. B., and Rao, V. B. (2017a). Bacteriophage T4 as a nanoparticle platform to display and deliver pathogen antigens: construction of an effective anthrax vaccine. Methods Mol. Biol. 1581, 255-267. doi: 10.1007/978-1-4939-6869-5_15

Tao, P., Mahalingam, M., Kirtley, M. L., Van Lier, C. J., Sha, J., Yeager, L. A., et al. (2013a). Mutated and bacteriophage T4 nanoparticle arrayed F1-V immunogens from Yersinia pestis as next generation plague vaccines. PLoS Pathog. 9:e1003495. doi: 10.1371/journal.ppat.1003495

Tao, P., Mahalingam, M., Marasa, B. S., Zhang, Z., Chopra, A. K., and Rao, V. B. (2013b). In vitro and in vivo delivery of genes and proteins using the bacteriophage T4 DNA packaging machine. Proc. Natl. Acad. Sci. USA 110, 5846-5851. doi: 10.1073/pnas.1300867110

Tao, P., Mahalingam, M., Zhu, J., Moayeri, M., Sha, J., Lawrence, W. S., et al. (2018a). A bacteriophage T4 nanoparticle-based dual vaccine against Anthrax and Plague. MBio 9, pii: e01926-18. doi: 10.1128/mBio.01926-18

Tao, P., Wu, X., and Rao, V. (2018b). Unexpected evolutionary benefit to phages imparted by bacterial CRISPR-Cas9. Sci. Adv. 4:eaar4134. doi: 10.1126/sciadv. aar4134

Tao, P., Wu, X., Tang, W. C., Zhu, J., and Rao, V. (2017b). Engineering of bacteriophage T4 genome using CRISPR-Cas9. ACS Synth. Biol. 6, 1952-1961. doi: 10.1021/acssynbio.7b00179

Tao, P., Zhu, J., Mahalingam, M., Batra, H., and Rao, V. B. (2018c). Bacteriophage T4 nanoparticles for vaccine delivery against infectious diseases. Adv. Drug Deliv. Rev. pii: S0169-409X(18)30164-9. doi: 10.1016/j.addr.2018.06.025

Thomason, L. C., Oppenheim, A. B., and Court, D. L. (2009). Modifying bacteriophage lambda with recombineering. Methods Mol. Biol. 501, 239-251. doi: 10.1007/978-1-60327-164-6_21

Tissot, A. C., Renhofa, R., Schmitz, N., Cielens, I., Meijerink, E., Ose, V., et al. (2010). Versatile virus-like particle carrier for epitope based vaccines. PLoS One 5:e9809. doi: 10.1371/journal.pone.0009809

Torres-Barcelo, C., Arias-Sanchez, F. I., Vasse, M., Ramsayer, J., Kaltz, O., and Hochberg, M. E. (2014). A window of opportunity to control the bacterial pathogen Pseudomonas aeruginosa combining antibiotics and phages. PLoS One 9:e106628. doi: 10.1371/journal.pone.0106628

Torres-Barcelo, C., and Hochberg, M. E. (2016). Evolutionary rationale for phages as complements of antibiotics. Trends Microbiol. 24, 249-256. doi: 10.1016/j.tim.2015.12.011

Verma, V., Harjai, K., and Chhibber, S. (2009). Restricting ciprofloxacin-induced resistant variant formation in biofilm of Klebsiella pneumoniae B5055 by complementary bacteriophage treatment. J. Antimicrob. Chemother. 64, 1212-1218. doi: $10.1093 / \mathrm{jac} / \mathrm{dkp} 360$

Viertel, T. M., Ritter, K., and Horz, H. P. (2014). Viruses versus bacteria-novel approaches to phage therapy as a tool against multidrug-resistant pathogens. J. Antimicrob. Chemother. 69, 2326-2336. doi: 10.1093/jac/dku173

Wittebole, X., De Roock, S., and Opal, S. M. (2014). A historical overview of bacteriophage therapy as an alternative to antibiotics for the treatment of bacterial pathogens. Virulence 5, 226-235. doi: 10.4161/viru.25991

Wright, A., Hawkins, C. H., Anggard, E. E., and Harper, D. R. (2009). A controlled clinical trial of a therapeutic bacteriophage preparation in chronic otitis due to antibiotic-resistant Pseudomonas aeruginosa; a preliminary report of efficacy. Clin. Otolaryngol. 34, 349-357. doi: 10.1111/j.1749-4486.2009.01973.x

Yoichi, M., Abe, M., Miyanaga, K., Unno, H., and Tanji, Y. (2005). Alteration of tail fiber protein gp38 enables T2 phage to infect Escherichia coli O157:H7. J. Biotechnol. 115, 101-107. doi: 10.1016/j.jbiotec.2004.08.003

Zepp, F. (2010). Principles of vaccine design-lessons from nature. Vaccine 28(Suppl. 3), C14-C24. doi: 10.1016/j.vaccine.2010.07.020

Zimecki, M., Weber-Dabrowska, B., Lusiak-Szelachowska, M., Mulczyk, M., Boratynski, J., Pozniak, G., et al. (2003). Bacteriophages provide regulatory signals in mitogen-induced murine splenocyte proliferation. Cell. Mol. Biol. Lett. 8, 699-711.

Conflict of Interest Statement: The authors declare that the research was conducted in the absence of any commercial or financial relationships that could be construed as a potential conflict of interest.

Copyright (๑) 2019 Chen, Batra, Dong, Chen, Rao and Tao. This is an open-access article distributed under the terms of the Creative Commons Attribution License (CC BY). The use, distribution or reproduction in other forums is permitted, provided the original author(s) and the copyright owner(s) are credited and that the original publication in this journal is cited, in accordance with accepted academic practice. No use, distribution or reproduction is permitted which does not comply with these terms. 